\title{
"A GENTE GOSTA É DE BRINCAR COM OS OUTROS MENINOS!" RELAÇÕES SOCIAIS ENTRE CRIANÇAS NUM JARDIM DE INFÂNCIA*
}

\section{Patrí́cia Dias Prado}

E

sta edição portuguesa corresponde à tese de doutoramento de Manuela Ferreira, ${ }^{1}$ intitulada: "A gente aqui o que gosta mais é de brincar com os outros meninos!", na Faculdade de Psicologia e Ciências da Educação da Universidade do Porto, no ano de 2002. Ater-me-ia, inicialmente, ao título da tese, uma vez que a própria edição é apresentada como sua forma (da tese) essencial em livro, pois entre o que "a gente aqui o que gosta mais é de brincar com os outros meninos" e "a gente gosta é de brincar com os outros meninos", há, do meu ponto de vista, importantes diferenciações que, no entanto, não escapam do olhar da pesquisadora quando propóe compreender o lugar das crianças como atores sociais, que participam do processo de formação e de transformação das regras da vida social e "os procedimentos que habitualmente as mobilizam para significar, construir e reconhecer o seu mundo da vida quotidiana, a partir de suas próprias perspectivas" (p. 25).

Além disso, a obra busca defender o lugar e o espaço das crianças pequenas em contexto educativo, num jardim de infância português (para crianças de 3 a 6 anos), a partir do campo teórico da Sociologia da Infância (Corsaro, Sirota, Montandon, dentre outros) e através da discussão e reflexão das implicações epistemológicas e metodológicas da pesquisa com crianças e a partir delas. ${ }^{2}$

Resenha do livro de Maria Manuela M. Ferreira (Porto, Portugal: Afrontamento, 2004).

** Doutoranda em educação e professora bolsista do curso de Pedagogia do Departamento de Ciências Sociais Aplicadas à Educação da Faculdade de Educação da Universidade Estadual de Campinas (UnICAMP). E-mail: patypra@mpc.com.br

Educ. Soc., Campinas, vol. 26, n. 91, p. 683-688, Maio/Ago. 2005 
“A gente gosta é de brincar com os outros meninos!”...

Para isso, a autora inclina-se sobre a observação e interpretação das interações que as crianças estabelecem com outras crianças e com os adultos (incluindo-a), dando significados e estruturando suas experiências sociais - assentada numa etnografia com crianças.

Descrevendo e analisando o processo através do qual era aceita e aceitava os sujeitos da pesquisa, a pesquisadora nos coloca seus "estranhos sabores" (p. 40) expressos como marcantes e marcadores desta etnografia e correspondentes aos estranhamentos e perplexidades enfrentados na pesquisa de campo entre os adultos e as crianças pesquisadas, na construção das relações através da observação participante no dia-a-dia das crianças e de suas brincadeiras.

Falando assim, "à porta do Jardim de Infância da Várzea”, a pesquisa apresenta a heterogeneidade social de um grupo de crianças (num total de 18 meninas e meninos de 3 a 6 anos de idade), localizando o entorno social que estão inseridas, suas famílias, comunidade, e também "da porta para dentro", abordando o cotidiano da instituição, sua organização espacial, temporal, o planejamento das atividades, as regras instituídas, os materiais e brincadeiras, evidenciando, assim como nas pesquisas brasileiras, uma rotina pré-determinada pelos profissionais e neles centrada, com regras prescritivas que orientam as ações e usos dos espaços e tempos, em que o encontro das crianças com outras de turmas diferentes é previsto somente nos momentos livres ou no "recreio".

De toda forma, Manuela concebe esta padronização das atividades sociais como fornecedoras, não só de "um sistema classificatório dos diferentes contextos, relações e actores, bem como um conjunto de regras que permite aos participantes estruturarem as ações como elementos seqüenciais das interaçôes sociais". Mas "é igualmente, um contexto que favorece desigualmente os diferentes poderes dos actores e que será por eles usado nas suas lutas e negociações" (p.102).

$\mathrm{Na}$ compartimentalização dos tempos e espaços das crianças, "dos meandros da ordem institucional adulta às ordens sociais intituintes das crianças" a obra traz não somente retratos da construção de ordem sociais no Jardim de Infância como também a revelação de um espaço de confrontos em que profissionais e crianças desenvolvem múltiplas e complexas interaçôes com sentidos e significados também diversos.

Assim como temos observado, aqui no Brasil, a capacidade de transgressão das crianças, a presente pesquisa também revela esta capa- 
cidade das crianças pequenas portuguesas investigadas, quando lançam mão de estratégias de resistência aos poderes arbitrários impostos pelas profissionais como, por exemplo, prolongando as brincadeiras, arrumando e desarrumando inúmeras vezes os espaços de brincadeira e os próprios brinquedos e materiais - por hora também se recusando à ordem de arrumar, por hora inventando uma nova brincadeira de brincar de arrumar, mas com outro sentido, diferente daquele estabelecido pelos profissionais que seria pondo as coisas no lugar: "- Estamos a arrumar tudo. Ainda não acabamos. Falta ainda...” (p. 138), diziam as crianças num exercício de solidariedade e de coletividade entre elas.

A partir dos pressupostos interacionistas, outras brincadeiras e formas de brincar são descritas e analisadas, além das arrumaçôes até as brincadeiras de faz-de-conta, que acredito não serem excludentes, em que as crianças desencadeiam outros processos sociais alicerçando uma cultura de pares, eu diria culturas no plural, ${ }^{3}$ a partir também de uma outra ordem, aquela advinda de seus próprios interesses, valores e regras. O desafio que se coloca, portanto, é de compreender esta ordem instituinte das crianças e a estruturação de seu grupo social.

Do conjunto das crianças pesquisadas, meninas e meninos, de 3 a 6 anos de idade, maiores e menores na compleição física, um grupo dos mais velhos e um grupo dos mais novos também pode ser identificado, mas que podem corresponder também ao percurso institucional (o tempo que freqüenta a instituição - os veteranos e os novatos).

No entanto, dado que a idade não corresponde a uma variável natural e que a variabilidade de desenvolvimento biológico, psicológico e social nem sempre permite estabelecer uma correspondência coerente entre tamanho, idade e competências, o facto de se ser mais frágil do ponto de vista físico não significa, necessariamente, ser mais novo, nem implica, do ponto de vista das interações, uma menor competência cognitiva ou social. (p. 76)

A importância desta afirmação, que vejo como contribuição essencial da obra, alimenta, subsidia e impulsiona a consolidação de uma pedagogia da infância que leve em conta a capacidade de as crianças estabelecerem relações diversas na diversidade (de gênero, de classe social, de idade, de tamanho...), assim como de produzirem saberes e construírem culturas infantis próprias dos grupos infantis no convívio coletivo.

A incoerência permitida ao não encontrarmos uma correspondência coerente entre tamanho, idade e competências entre as crianças pe- 
“A gente gosta é de brincar com os outros meninos!”...

quenas coloca, pois, em questão, a própria noção de coerência e as suas bases. Se as crianças nos surpreendem, propondo o inusitado, o imprevisto num espaço previsto, planejado e organizado pelos adultos, então não detemos o controle sobre seus pensamentos e atitudes como ousamos. O enigma da infância já discutido por Jorge Larrosa (1998, p. 229-246) aqui se apresenta na capacidade de as crianças pequenas portuguesas, meninas e meninos, construírem ordens próprias, estruturarem grupos de pares heterogêneos e se apropriam de formas diferenciadas do espaço-tempo institucional pesquisado através das brincadeiras.

Diferentemente do que a literatura especializada sugeria, não haver interaçóes complexas ou duradouras entre as crianças pequenas, esta obra confirma e reintegra os estudos recentes no campo da educação infantil brasileira e os estudos italianos não tão recentes, de que as atividades, interações, relações entre as crianças nestes espaços não dependem de seus níveis de competências ou habilidades, sejam lingüísticas, cognitivas, motoras, perceptivas etc. - categorias herdadas de campos teóricos, que se interessaram, desde seu início, pela pesquisa com crianças, como a psicologia e a medicina, mas que assim também etapizam os seres humanos e suas condições humanas. ${ }^{4}$

Pesquisando crianças pequenas em creches públicas brasileiras, ${ }^{5}$ também percebi que elas

(...) transgrediam a divisão etária proposta no contexto da creche, aquela utilizada em todo o sistema escolar, que parte de uma concepção de infância como algo que se compartimentaliza em fases tão delimitáveis que, quase naturalmente, coloca às crianças um modelo definitivo e definidor na construção de seu desenvolvimento e de sua identidade social, reforçada pelas teorias etapistas de desenvolvimento infantil e por pré-noções em relação à infância, como por exemplo, que as crianças maiores machucam as crianças menores ou que crianças maiores e menores não sabem brincar juntas, dentre tantas outras. (Prado, 2002, p. 106)

Da mesma forma e propondo "virar o quotidiano do avesso" (p. 411), denunciando formas de adestramento, de cerceamento da criatividade e da liberdade das crianças, a autora, além de denunciar uma relação adulto-criança pautada numa cultura escolar que valoriza um corpo racional, dócil, passivo, disciplinado e submisso em detrimento ao corpo curioso e ativo, aponta para a possibilidade do Jardim de Infância como espaço presente de cidadania através da garantia do direito das crianças à brincadeira. 
Para tanto, dando voz e vez às crianças, em suas proporções e intensidades, a obra revela corpos diversos construídos e constitutivos da e na dinâmica social, sujeitos que questionam os valores do mundo adulto e que reclamam também por um adulto aprendiz que observa, que conhece a criança e tenta responder às necessidades e ao inesperado; que constrói uma relação pedagógica de 'mão dupla', em que aquele que tem o papel de ensinar acaba também por aprender (Bufalo, 1997).

Esta obra é uma referência para aqueles que, de alguma forma, interessam-se pelas questóes relativas à infância, sua educação e seu mundo de cultura, pesquisadores, estudantes e profissionais da educação, especialmente da educação das crianças pequenas, pois vem apontar para um estudo atual que permite a análise de paradigmas teóricos, a discussão de possibilidades metodológicas na pesquisa com crianças, valorizando-as como construtoras de conhecimento que são.

Assim, também como pesquisadora e militante na luta pela direito das crianças à infância e à brincadeira, tenho me perguntando o que as crianças têm nos ensinado? Quais as implicaçóes destes ensinamentos para a construção de uma pedagogia da educação infantil que conheça quem são as crianças e o que elas estão produzindo para além das determinações desenvolvimentistas, contrariando o que lhes é imposto pela idade, pela classe social, pelo tamanho, pela etnia, pelo gênero? O que estamos conhecendo das crianças e com elas aprendendo? Quais as culturas infantis que elas estão produzindo nos espaços educativos? Manuela Ferreira parece engajar-se nesta luta apresentando-nos, pois, as crianças pequenas portuguesas, sua educação e cultura.

\section{Notas}

1. Conhecida por nós pesquisadoras(es) de infância brasileiras(os) pela participação e apresentação de sua pesquisa na Reuniāo Anual da Associação Nacional de Pós-Graduação e Pesquisa em Educação (ANPED), em 2004.

2. A riquíssima bibliografia apresentada aponta para as vertentes francesa e americana (além dos estudos realizados em Portugal) na constituição de uma sociologia da infância que, além de estudar as crianças, propõe que seus pontos de vista sejam levados em consideração, buscando compreender as crianças não apenas como um vir-a-ser, mas como crianças hoje, no presente.

3. Como já evidenciado por Florestan Fernandes (em Folclore e mudança social na cidade de São Paulo, Petrópolis: Vozes, 1979), através do estudo dos folguedos entre grupos infantis, as culturas que as crianças produziam na diversidade e, desde então, pode-se dizer que uma Sociologia da Infância no Brasil é inaugurada.

Educ. Soc., Campinas, vol. 26, n. 91, p. 683-688, Maio/Ago. 2005 
“A gente gosta é de brincar com os outros meninos!”...

4. Uma Sociologia da Infância, campo amplo em construção, também se constitui a partir dos estudos brasileiros e italianos sobre a infância, de forma concomitante ao repertório teórico apresentado pela autora, pois ambos demarcam a necessidade de ruptura com as concepçōes etapistas sobre a infância, como preparatória para fases posteriores e para o ensino obrigatório.

5. Desde de meus estudos de mestrado como agora no doutorado, ambos sob a orientação da professora Neusa Maria Mendes de Gusmão.

\section{Referências bibliográficas}

LARROSA, J. O enigma da infância: ou o que vai do possível ao verdadeiro. In: Pedagogia profana: danças, piruetas e mascaradas. Porto Alegre/ RS: Contrabando, 1998. p. 229-246.

FERNANDES, F. Folclore e mudança social na cidade de São Paulo. Petrópolis: Vozes, 1979.

PRADO, P.D. Quer brincar comigo? Pesquisa, brincadeira e educação infantil. In: Faria, A.L.G.; Demartini, Z.B.; Prado, P.D. (Org.). Por uma cultura da infância: metodologias de pesquisa com crianças. Campinas: Autores Associados, 2002, p. 106.

BUFALO, J.M.P. Creche: lugar de criança, lugar de infância. Um estudo sobre as práticas educativas em um CEMEI de Campinas/SP. 1997. Dissertação (mestrado) - Faculdade de Educação. Universidade Estadual de Campinas, Campinas. 